
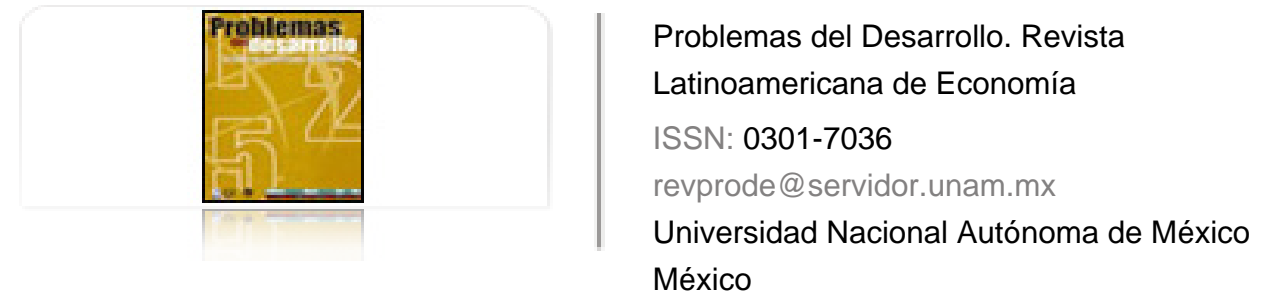

Conte Grand, Mariana; D'Elia, Vanesa

La política ambiental en América Latina y el Caribe

Problemas del Desarrollo. Revista Latinoamericana de Economía, vol. 39, núm. 154, julio-septiembre, 2008, pp. 111-134

Universidad Nacional Autónoma de México

Distrito Federal, México

Disponible en: http://www.redalyc.org/articulo.oa?id=11820139006

Cómo citar el artículo

- Número completo

- Más información del artículo

Página de la revista en redalyc.org

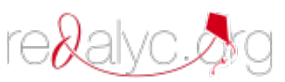

Sistema de Información Científica

Red de Revistas Científicas de América Latina, el Caribe, España y Portugal Proyecto académico sin fines de lucro, desarrollado bajo la iniciativa de acceso abierto 


\title{
LA POLÍTICA AMBIENTAL EN AMÉRICA LATINA Y EL CARIBE
}

\author{
Mariana Conte Grand* \\ Vanesa D'Elia**
}

Fecha de recepción: 14 de febrero de 2008. Fecha de aceptación: 19 de mayo de 2008.

\section{Resumen}

Este trabajo intenta evaluar los determinantes para que países de la región adopten políticas ambientales activas. Se toman como referencia dos indicadores de política ambiental internacional: el número de tratados internacionales ratificados referidos al tema, y el cumplimiento con los programas sugeridos por la Agenda 21. Los únicos factores importantes para evaluar si los gobiernos de la región van a tener políticas más activas en favor de la conservación del medio parecen ser el grado de desarrollo humano (que mide el crecimiento en tres dimensiones: educación, esperanza de vida e ingresos) y la presión demográfica. Los sistemas políticos y el estatus ambiental de las naciones no parecen influir en políticas ecológicas más activas. Los resultados son robustos a distintas especificaciones.

Palabras clave: política ambiental, desarrollo sostenible, América Latina y el Caribe, tratados internacionales, región.

* Directora del Departamento de Economía de la Universidad del CEMA (Centro de Estudios Macroeconómicos de Argentina). Correo electrónico: mcg@cema.edu.ar.

** Jefa del Área Análisis Integral de la Seguridad Social de la Administración Nacional de la Seguridad Social (ANSES). Correo electrónico: vanesadelia@anses.gov.ar.

Una versión previa de este trabajo fue publicada en Bosoer F. y F. Calle (eds.), 2010: una agenda para la región, noviembre 2006, TAEDA Editora, Buenos Aires, Argentina. Esta nueva versión amplía la anterior en cuanto a la revisión de la literatura, a los datos empleados y a la estrategia empírica. Los puntos de vista de las autoras no necesariamente representan las posiciones de las instituciones en las que se desempeñan. 


\section{Abstract}

This study aims to assess the determinants for countries in the region adopting active environmental policies. It takes as a reference two indicators of international environmental policy: the number of ratified international treaties that refer to this matter and the fulfilment of programs suggested by Agenda 21. The only important factors for evaluating whether the governments of the region are going to have more active policies in favor of environmental conservation seem to be the degree of human development (which measures growth in three dimensions: education, life expectancy and income levels) and demographic pressure. Political systems and the environmental status of countries do not seem to influence more active ecological policies. The results are robust for differing specifications.

Key words: environmental policy, sustainable development, Latin America and the Caribbean, international treaties, region.

\section{Résumé}

Ce travail tente d'évaluer les facteurs déteminants pour que des pays de la région adoptent des poitiques environnementales actives. Deux indicateurs de politique environnementale intenationale sont pris comme références: le nombre de traités internationaux ratifiés qui se réfèrent à la question, et la mise en œuvre des programmes suggérés par l'Agenda 21. Les seuls éléments importants pour évaluer si les gouvernement de la région vont mener des politiques plus actives en matière de protection de l'environnement semblent être l'indice de développement humain (qui prend en compte trois indices de croissance: éducation, espérance de vie et revenus) et la pression démographique. Les systèmes politiques et l'état de l'environnement des nations ne semblent pas influer sur l'adoption de politiques écologiques plus actives. Les résultats satisfont diverses spécifications.

Mots clés: polítique environnementale, développement durable, Amérique Latine et Caraïbes, traités internationaux, region.

\section{Resumo}

Este trabalho tenta avaliar os determinantes para que paises da região adotem políticas ambientais ativas, se tomam como referência os indicadores de política ambiental internacional ratificado referido ao tema, e o cumprimento com os programas sugeridos pela Agenda 21. Os únicos fatores importantes para avaliar se os governos da região terão políticas mais ativas em favor da conservação do meio parecem ser o grau de desenvolvimento humano (que mede o crescimento em três dimensões: educação, esperança de vida e ingressos) e a pressão demográfica. Os sistemas políticos e o estatus ambiental das nações não parecem influir em políticas ecológicas mais ativas. Os resultados são sólidos a distintas especificações.

Palavras chave: política ambiental, desenvolvimento sustentável, América Latina e o Caribe, tratados internacionais, região. 


\section{Introducción}

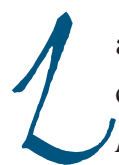

a política ambiental es uno de los tres pilares del desarrollo sostenible, junto con el bienestar social y el económico. Este concepto nació en el documento Nuestro futuro común, conocido como el Informe Brundtland (1987). ${ }^{1}$ Esta definición fue luego adoptada como el Principio 3 de la Declaración de Río, la cual siguió a la famosa Cumbre de la Tierra realizada en 1992 en Río de Janeiro (Brasil). Allí se definió como desarrollo sostenible "aquel desarrollo que satisface las necesidades de las generaciones presentes sin comprometer las posibilidades de las del futuro para atender sus propias necesidades". Para que los distintos países pudieran concretar esa meta de alcanzar el desarrollo sostenible, en la Cumbre de Río, la mayoría de los gobiernos allí reunidos decidieron adoptar el Programa 21 (también llamado Agenda 21). Éste consiste en guías de acción concretas con vista a alcanzar el desarrollo sostenible.

Ahora bien, en ese marco vale la pena preguntarse cómo se ubican los distintos países de Latinoamérica en el camino hacia el desarrollo sostenible. Esto es, si hay naciones que están más cerca que otras de lograrlo y de qué depende que las que estén lejos se puedan ir acercando. De esta manera se busca indagar cuáles serían los determinantes para que los distintos Estados de Latinoamérica y el Caribe adopten políticas ambientales.

Es difícil considerar para los distintos países medidas homogéneas de su "política ambiental". Por ello, se ha decidido tomar dos indicadores relativamente objetivos relacionados con la política ambiental internacional: 1) el número de tratados internacionales ratificados por cada uno de los gobiernos y 2) el número de medidas aplicadas para cumplir las metas de la Agenda 21. Ambos indicadores se eligen porque pueden obtenerse sin dificultad de fuentes internacionales comparables (UN, 2002). ${ }^{2}$

Este artículo se organiza como sigue. En primer lugar se analiza la situación actual de cada uno de los países de la región respecto a su política ambiental medida con los dos indicadores arriba indicados. En la siguiente sección se sintetizan y discuten las distintas variables que definen a cada país en términos de sus condiciones políticas y económicas así como su situación ambiental de base, para identificar el posible origen de las diferencias en la política ambiental. Conocer estos determinantes permite inferir las posibilidades de cada país de acercarse a dar cumplimiento al desarrollo sostenible según sus características. Más adelante se vinculan los distintos

1 La Primera Ministra Sueca (Gro Harlem Brundtland) era en ese momento coordinadora de la Comisión de Medio Ambiente y Desarrollo de las Naciones Unidas.

2 Estos dos indicadores son los mismos que los utilizados en Tonn (2007). 
determinantes nacionales (económicos, políticos y ambientales) con los indicadores de política ambiental internacional y se hacen varios análisis de sensibilidad para verificar la fortaleza de dicho vínculo. Finalmente, se presentan las conclusiones.

\section{Indicadores de la política ambiental internacional}

Es difícil considerar para los distintos países medidas homogéneas de su "política ambiental". Ello implicaría buscar para cada uno, por ejemplo, cuáles son sus políticas locales sobre calidad de agua o de aire. Por eso, se toman aquí en consideración las políticas ambientales internacionales, pues hay datos compilados para las distintas naciones de manera casi completa y en formatos comparables. ${ }^{3}$

En particular, se consideran dos indicadores relativamente objetivos relacionados con la política ambiental internacional: 1) el número de tratados internacionales ratificados por cada uno de los países y 2) el número de medidas aplicadas para cumplir con las metas de la Agenda 21. Ambos indicadores son tomados de un informe relativamente reciente de las Naciones Unidas (UN, 2002).

En el primer caso, se trata de considerar cuáles son de los principales tratados ambientales internacionales ratificados por cada uno de los países. Estos tratados incluyen cuestiones de biodiversidad, cambio climático, especies en peligro, ozono, océanos, etcétera. En el segundo caso (el de la aplicación de la Agenda 21) se trata de conocer cuántas de las 19 metas concretas de la Agenda 21 han sido o están en proceso de llevarse a la práctica por cada gobierno. Estas metas tienen que ver con el establecimiento de bases de datos de químicos, monitoreo de la biodiversidad, la concreción de campañas orientadas al ahorro de energía por parte de los consumidores, etcétera. El Anexo A describe con mayor precisión los tratados incluidos en el primer indicador así como las acciones para cumplir con la Agenda 21.

El cuadro 1 reporta los resultados obtenidos de la recopilación de información de estos indicadores para países de América Latina y el Caribe. Si se compara esta región con las 190 naciones del mundo incluidas en Tonn (2007), se observa, por un lado, que los países de la región han ratificado, en promedio, nueve tratados internacionales, uno más que la media internacional. Pero si se miran las acciones concretas hacia un ambiente más saludable (es decir, las de la Agenda 21), el cumplimiento medio de Latinoamérica y el Caribe es de 33\% de las acciones de la Agenda 21, menor que 39\%

3 Ello no quiere decir que no existan otros datos de comportamiento ambiental en el rubro país que sean comparables. Por ejemplo, Esty y Porter (2002) elaboraron un índice de la fortaleza de la política ambiental para varias naciones. 
del promedio del mundo. O sea, que la región sería más proclive a ratificar tratados que la adopción de políticas específicas como las de la Agenda 21.

En cuanto a las diferencias entre los distintos países de la región, surge claramente del cuadro 1 que hay mucha disparidad en su acercamiento al tema ambiental. Naciones como México lideran ambos indicadores, mientras que otras como Haití o República Dominicana llevan los últimos lugares. En efecto, México ha ratificado todos los tratados ambientales relevantes y tiene en marcha políticas para $84 \%$ de las medidas concretas establecidas como metas en la Agenda 21. Ello es muy diferente de Haití, que ha ratificado solamente cinco tratados y tomado medidas para menos de $11 \%$ de las metas de la Agenda 21.

Cuadro 1

Indicadores de política ambiental internacional para países de Latinoamérica y el Caribe

\begin{tabular}{|c|c|c|c|c|}
\hline \multirow[b]{2}{*}{ País } & \multicolumn{2}{|c|}{ Ratificación acuerdos internacionales } & \multicolumn{2}{|c|}{ Aplicación AGENDA 21} \\
\hline & $\begin{array}{l}\text { Acuerdos } \\
\text { ratificados }\end{array}$ & en $\%$ & $\begin{array}{c}\text { Metas } \\
\text { realizadas }\end{array}$ & $\begin{array}{l}\text { en \% (ajustado } \\
\text { si no aplica) }\end{array}$ \\
\hline Antigua y Barbuda & 8 & 72.73 & 1 & 5.26 \\
\hline Argentina & 10 & 90.91 & 5 & 26.32 \\
\hline Bahamas & 9 & 81.82 & 9 & 47.37 \\
\hline Barbados & 9 & 81.82 & 14 & 73.68 \\
\hline Belize & 8 & 72.73 & 0 & 0.00 \\
\hline Bolivia & 11 & 100.00 & 7 & 36.84 \\
\hline Brasil & 10 & 90.91 & 11 & 57.89 \\
\hline Chile & 9 & 81.82 & 13 & 68.42 \\
\hline Colombia & 9 & 81.82 & 12 & 63.16 \\
\hline Costa Rica & 10 & 90.91 & 12 & 66.67 \\
\hline Cuba & 10 & 90.91 & 14 & 73.68 \\
\hline Dominica & 8 & 72.73 & 0 & 0.00 \\
\hline Ecuador & 10 & 90.91 & 6 & 31.58 \\
\hline El Salvador & 8 & 72.73 & 9 & 47.37 \\
\hline Grenada & 7 & 63.64 & 0 & 0.00 \\
\hline Guatemala & 10 & 90.91 & 0 & 0.00 \\
\hline Guyana & 7 & 63.64 & 7 & 36.84 \\
\hline Haití & 5 & 45.45 & 2 & 10.53 \\
\hline Honduras & 10 & 90.91 & 10 & 52.63 \\
\hline Jamaica & 9 & 81.82 & 4 & 21.05 \\
\hline México & 11 & 100.00 & 16 & 84.21 \\
\hline Nicaragua & 10 & 90.91 & 11 & 61.11 \\
\hline Panamá & 10 & 90.91 & 5 & 26.32 \\
\hline Paraguay & 10 & 90.91 & 6 & 35.29 \\
\hline Perú & 9 & 81.82 & 6 & 31.58 \\
\hline República Dominicana & 7 & 63.64 & 2 & 10.53 \\
\hline San Cristóbal y Nieves & 8 & 72.73 & 0 & 0.00 \\
\hline Santa Lucía & 8 & 72.73 & 4 & 21.05 \\
\hline San Vicente y las Granadinas & 7 & 63.64 & 0 & 0.00 \\
\hline Suriname & 7 & 63.64 & 5 & 26.32 \\
\hline Trinidad \& Tobago & 10 & 90.91 & 0 & 0.00 \\
\hline Uruguay & 9 & 81.82 & 2 & 10.53 \\
\hline Venezuela & 9 & 81.82 & 11 & 57.89 \\
\hline Promedio & 9 & $80 \%$ & 6 & $33 \%$ \\
\hline
\end{tabular}

Nota: Elaboración propia con base en UN (2002). 
Por otro lado, también puede verse en el cuadro 1 que los dos indicadores no reflejan la misma imagen de la preocupación ambiental de los países, de allí la utilidad de considerar ambos. Por ejemplo, si bien Argentina o Panamá han ratificado casi todos los tratados (10 de 11), han tomado muy pocas acciones para cumplir con la Agenda 21 (26\% de todas las que deberían haber llevado a cabo).

En este artículo se mantienen los dos indicadores de manera separada (y no se usa un índice con algún tipo de promedio) para determinar si los predictores de la firma (y posterior ratificación) de tratados ambientales difieren de los de la decisión de adoptar acciones concretas como las de la Agenda 21. Por ejemplo, es posible que las decisiones referidas a la ratificación de tratados estén más influidas por cuestiones como condicionamientos para recibir ayuda internacional o requisitos de tratados de comercio que las decisiones referidas a la Agenda 21. La ratificación de un tratado es un condicionamiento más visible y más fácil de dar seguimiento que la construcción de una base de datos o de campañas de educación ambiental. Pero también puede darse que se justifiquen presiones hacia arriba en los dos indicadores por acuerdos comerciales como el Tratado de Libre Comercio de América del Norte (TLCAN) en el caso de México, o simplemente por alineamientos entre países de la región y países desarrollados (véase al respecto Barro y Conte Grand, 2002 para Argentina y Estados Unidos).

\section{Posibles determinantes de la política ambiental}

Existe una serie de creencias sobre cuáles pueden ser los determinantes que favorecen la adopción de una política ambiental u otra.

La más conocida de las teorías a este respecto considera que lo crucial para tener políticas ambientales más activas es el nivel de ingreso del país. Esa literatura conocida como de la "U ambiental de Kuznets" establece que a medida que las naciones van creciendo, contaminan más porque las personas están más interesadas en el trabajo y en el ingreso que en la calidad ambiental, la comunidad es muy pobre para pagar reducciones de contaminación, las tecnologías son relativamente poco orientadas a cuidar el ambiente y, por ende, la regulación ambiental es débil. ${ }^{4}$ Pero llega un momento que con cierto nivel de riqueza estos argumentos se revierten, se comienzan a tomar medidas de política ambiental y la contaminación baja. Este cambio en la dirección de la curva ocurriría normalmente entre los 5,000 y 8,000 dólares per capita.

4 El trabajo original de Kuznets (Kuznets, 1955) trataba sobre un mismo tipo de relación en forma de U invertida entre desigualdad en la distribución del ingreso y desarrollo. 
El trabajo pionero en esta temática es el de Grossman y Krueger (1995), que ha seguido un área importante de la literatura en economía ambiental (véase una reseña en Dasgupta et al., 2002). Sin embargo, también ha habido críticas que señalan que en realidad la forma de $\mathrm{U}$ invertida es poco robusta a cambios en los datos, las formas funcionales y los métodos econométricos utilizados en las estimaciones (véase Harbaugh et al., 2002, entre otros).

A veces, en términos de contaminación, los trabajos utilizan como medida de política ambiental el resultado de ésta. Por ejemplo, una de las bases más utilizadas es la de calidad de aire y agua administrada por GEMS (Global Environmental Monitoring System). En otros casos, como en Congleton (1992), entre otros, se trata de "medir" política ambiental no por medio de la contaminación, sino por la adopción de políticas ambientales internacionales.

No tenemos motivos a priori para pensar que la relación entre ratificación de tratados internacionales y cumplimiento de la Agenda 21 y Producto Interno Bruto (PIB) per capita de los países latinoamericanos deba ser en un sentido u otro (véase figura 1).

Gráfica 1

Relación entre indicadores de política ambiental y PIB per capita
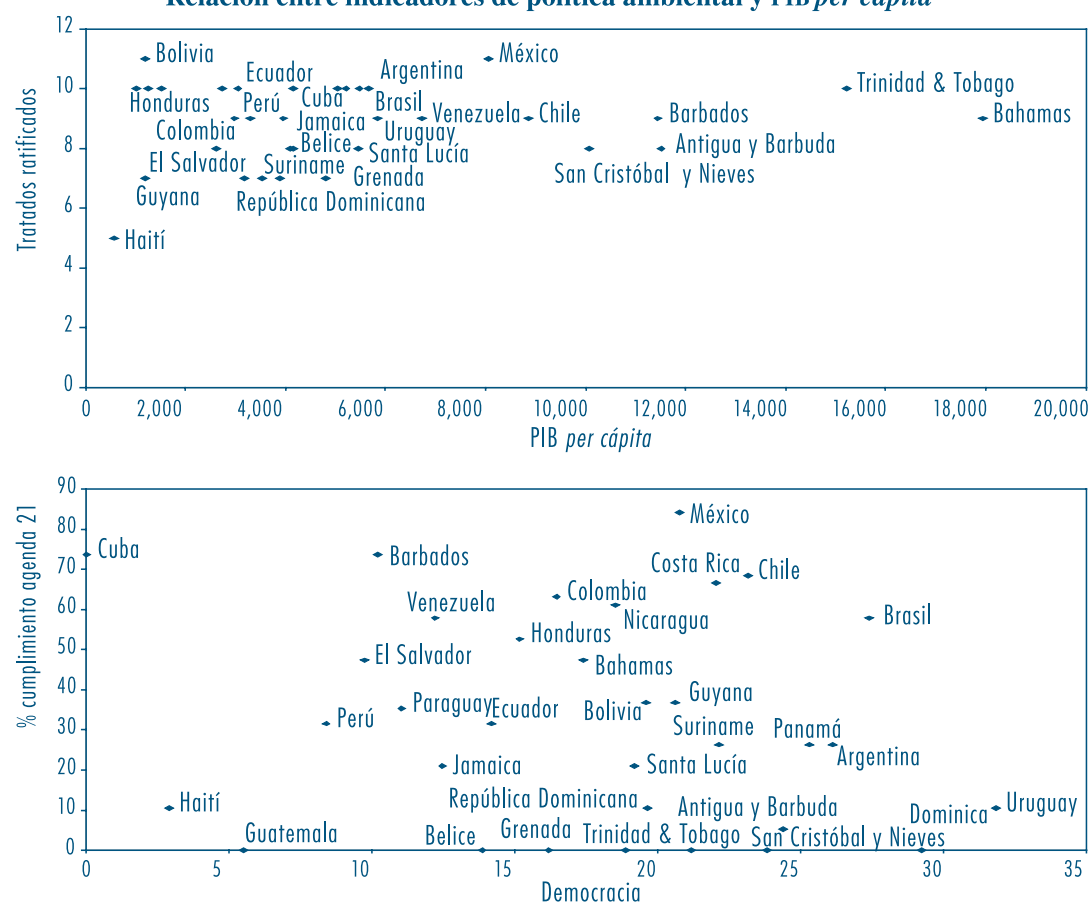

Fuente: Elaboración propia con base en UN (2006) y UNDP (2006). 
Por otro lado, resulta bastante razonable pensar que las políticas ambientales podrían depender no sólo del ingreso de un país, sino de las condiciones políticas que en él imperan. La literatura en ese sentido es también muy extensa. Uno de los trabajos pioneros, Congleton (1992), predice que los regímenes democráticos tienden a políticas ambientales más estrictas, pues esos gobiernos tienden a tener un horizonte de tiempo más largo (por ejemplo, no piensan que van a ser sacados del poder) que los autoritarios. Dicha predicción es confirmada tomando como variables dependientes dos tratados internacionales (la Convención de Viena y el Protocolo de Montreal) y variables dependientes relacionadas con la superficie, la población, el sistema capitalista o socialista, además de un índice de democracia.

En general, para los análisis empíricos, por ejemplo, se utilizan índices referidos a libertades civiles y políticas como los de Freedom House usados por Congleton (1992), indicadores de democracia como participación de los partidos minoritarios en las elecciones o porcentaje de la población que vota durante las elecciones (Vanhanen, Centre for the Study of Civil War), o promedios de libertades civiles y políticas como el índice Polity de la Universidad de Maryland.

La asociación positiva entre democracia y cuidado del ambiente para un conjunto amplio de países es encontrada más recientemente por Barrett y Grady (2000), Neumayer (2002) y Fredriksson y Wollscheid (2007), entre otros. Barrett y Grady (2000), por ejemplo, con datos en panel y la fuente Freedom House para su variable democracia, encuentran que países con niveles altos de respeto por los derechos civiles y políticos tienden a tener niveles bajos de contaminación de agua y de aire. Por otro lado, Neumayer (2002), con cuatro medidas diferentes para la variable democracia, índice de derechos civiles y políticos basado en los datos de Freedom House, índice del proyecto Polity, índice de democracia de Vanhanen, y un indicador de gobernancia del Banco Mundial), encuentra una relación positiva significativa entre democracia y compromiso ambiental (medido por la firma de tratados ambientales), pero mucho más débil entre democracia y resultado ambiental (medido en términos de calidad de ambiente). Por su parte, en Fredriksson y Wollscheid (2007), la relación positiva entre democracia y ambiente aparece primariamente determinada por las democracias parlamentarias. Esto es, los sistemas de gobierno como el presidencialismo deciden políticas ambientales no muy diferentes que las autocracias, y peores que las democracias parlamentarias.

Finalmente, en sentido contrario, Midlarsky (1998) en un análisis de sensibilidad sobre esta relación, con diferentes variables explicativas y dependientes, concluye que debe reexaminarse el resultado de que democracia y cuidado del ambiente están 
positivamente relacionados, pues ello no ocurre en todos los casos estudiados. Tonn (2007), con base en 190 países en el mundo, es más contundente en cuanto a que encuentra una asociación negativa entre democracia y políticas ambientales internacionales. Ello nos lleva a pensar que la relación entre tratados ratificados u Agenda 21 y las variables políticas para la región de estudio podría resultar positiva o negativa.

Sin embargo, el régimen político no parece ser la única variable política relevante. Otros autores como Pellegrini y Gerlagh (2006), con índices de Freedom House, encuentran que no hay una relación estrecha directa entre democracia y políticas ambientales, empero, controlando por el régimen político, la corrupción es un determinante importante (con signo negativo) de las políticas ambientales. De manera similar, Farzin y Bond (2006) y trabajos anteriores como el de Scruggs (1998) encuentran que el signo de la relación entre democracia y contaminación depende de factores adicionales, por ejemplo, la desigualdad en la distribución del ingreso.

Además del ingreso y del régimen político, otras variables han sido analizadas en la literatura como determinantes de la fortaleza de las políticas ambientales: la cantidad de población, educación, indicadores ambientales, etcétera. Tonn (2007) considera una lista muy exhaustiva de variables que pueden tener influencia en la propensión a adoptar políticas ambientales mirando hacia el futuro y encuentra relaciones positivas con tener más problemas ambientales o ante mayores presiones demográficas. ${ }^{5}$

En este trabajo, como determinantes del compromiso ambiental internacional en los países de América Latina y el Caribe, se consideran variables relacionadas sobre todo con 1) cuestiones económicas y condiciones de vida (ello incluye variables como PIB, población, densidad poblacional, educación, expectativa de vida, etcétera), 2) régimen político (nivel de democracia, grado en que se respetan los derechos de los ciudadanos y grado de corrupción), y 3) situación del país en cuanto a sus recursos naturales y a la contaminación (medidas a través de indicadores de cambio climático, de protección de especies en peligro y a la presencia de organizaciones ambientales).

En el cuadro 2 se detalla cuáles son dichas variables así como sus fuentes. En el cuadro 3 se proveen los valores mínimos, medios y máximos de cada una de estas variables. El detalle para cada uno de los países puede verse en el Anexo B.

5 Considera además, por ejemplo, variables relacionadas a la religión mayoritaria en cada país y a la base constitucional. Sin embargo, este tipo de variables no fueron incluidas en el análisis debido a la escasa variabilidad que presentan para los países de Latinoamérica (75\% de los países considerados tiene como religión mayoritaria la católica y un gobierno republicano). 
Cuadro 2

Posibles determinantes de la política ambiental

\begin{tabular}{|c|c|c|c|c|}
\hline Variable & Nombre completo & Definición & Fuente & Año \\
\hline HDI & $\begin{array}{l}\text { Índice de Desarrollo } \\
\text { Humano }\end{array}$ & $\begin{array}{l}\text { Se compone de una serie de variables que miden el } \\
\text { desarrollo humano como la expectativa de vida, } \\
\text { educación e ingreso. Esta variable toma valores } \\
\text { dentro del rango }[0,1]\end{array}$ & UNDP & 2004 \\
\hline $\mathrm{PIB} / \mathrm{cap}$ & $\begin{array}{l}\text { Producto Interno } \\
\text { Bruto per capita }\end{array}$ & Medido en dólares. & UNDP & 2006 \\
\hline VidaX & $\begin{array}{l}\text { Índice de } \\
\text { Expectativa de Vida }\end{array}$ & $\begin{array}{l}\text { Compuesta por un conjunto de variables que miden } \\
\text { la expectativa de vida. Puede tomar valores entre } \\
0 \text { y } 1 \text {. }\end{array}$ & UNDP & 2004 \\
\hline EducX & Índice de Educación & $\begin{array}{l}\text { Este índice está conformado por un conjunto de } \\
\text { variables que miden el cumplimiento de objetivos } \\
\text { educativos. Éste toma valores en el rango }[0,1]\end{array}$ & UNDP & 2004 \\
\hline Densidad & $\begin{array}{l}\text { Densidad de } \\
\text { Población }\end{array}$ & Mide la población por kilómetro cuadrado. & $\begin{array}{l}\text { Banco } \\
\text { Mundial }\end{array}$ & 2005 \\
\hline GR2050 & $\begin{array}{l}\text { Cambio porcentual } \\
\text { en la población } \\
20042050\end{array}$ & $\begin{array}{l}\text { Mide el cambio en la población proyectada entre el } \\
\text { año } 2004 \text { y } 2050\end{array}$ & CIESIN & 2005 \\
\hline $\begin{array}{l}\text { Derechos } \\
\text { Totales }\end{array}$ & $\begin{array}{l}\text { Índice de Derechos } \\
\text { Totales }\end{array}$ & $\begin{array}{l}\text { Definido como la suma del índice de derechos } \\
\text { políticos y el índice de derechos civiles. Toma } \\
\text { valores dentro del rango [2.14] donde la categoría } \\
\text { más alta indica menor protección constitucional. }\end{array}$ & $\begin{array}{l}\text { Freedom } \\
\text { House }\end{array}$ & 2007 \\
\hline CIVLIB & $\begin{array}{l}\text { Libertades Civiles y } \\
\text { Políticas }\end{array}$ & $\begin{array}{l}\text { Promedio de los índices de libertad civil y política. } \\
\text { Toma valores dentro del rango }[1,7]\end{array}$ & $\begin{array}{l}\text { Freedom } \\
\text { House }\end{array}$ & 2007 \\
\hline Democracia & $\begin{array}{l}\text { Índice de } \\
\text { Democracia }\end{array}$ & $\begin{array}{l}\text { Este índice combina dos indicadores: competencia } \\
\text { (se refiere a la participación de los partidos políticos } \\
\text { minoritarios en las elecciones) y participación } \\
\text { (vinculado al porcentaje de la población que vota } \\
\text { durante las elecciones). }\end{array}$ & $\begin{array}{l}\text { Vanhanen, } \\
\text { en CSCW }\end{array}$ & 2000 \\
\hline Graft & Corrupción & $\begin{array}{l}\text { Mide la habilidad para evadir regulaciones } \\
\text { ambientales y las responsabilidades de los daños } \\
\text { causados. A mayor indicador, más efectivo el control } \\
\text { de la corrupción. }\end{array}$ & CIESIN & 2005 \\
\hline IUCN & $\begin{array}{l}\text { Organización } \\
\text { Internacional } \\
\text { Ambiental }\end{array}$ & $\begin{array}{l}\text { Mide el número de organizaciones (gubernamentales } \\
\text { y ONG) por millones de habitantes. }\end{array}$ & CIESIN & 2005 \\
\hline $\mathrm{CO} 2 \mathrm{PC}$ & $\begin{array}{l}\text { Emisiones de carbón } \\
\text { per capita }\end{array}$ & $\begin{array}{l}\text { Mide las emisiones de dióxido de carbono per capita } \\
\text { en toneladas. }\end{array}$ & CIESIN & 2005 \\
\hline Ecorisk & Biodiversidad & $\begin{array}{l}\text { Mide el porcentaje del territorio de cada país con } \\
\text { especies animales y vegetales en riesgo de extinción. }\end{array}$ & CIESIN & 2005 \\
\hline
\end{tabular}

\section{Desaarrollo}


Si se comparan las medias para estas variables en Latinoamérica con los promedios mundiales, se verifica que en cuestiones económicas, el ingreso per capita es menor en promedio en Latinoamérica que en el mundo (5,323 versus 5,807 dólares), aunque esta diferencia no es significativa. Sin embargo, al considerar otros indicadores relacionados con el desarrollo esta situación se revierte: Latinoamérica presenta un índice de educación más elevado que el promedio mundial ( 0.84 versus 0.77 ) y mayor índice de expectativa de vida (0.77 para Latinoamérica y 0.67 para el mundo).

Cuadro 3

Estadísticos descriptivos de las variables determinantes de política ambiental

\begin{tabular}{lrrrr}
\hline \multicolumn{1}{c}{ Variables } & Media & Desvío Estándar & Mínimo & Máximo \\
\hline HDI & 0.77 & 0.075 & 0.482 & 0.879 \\
PIB per capita & 5,323 & 4,066 & 574 & 17,943 \\
Vidax & 0.77 & 0.085 & 0.450 & 0.890 \\
Educx & 0.84 & 0.088 & 1 & 0.960 \\
Densidad & 124.48 & 141.967 & 3 & 628 \\
GR2050 & 40.48 & 39.768 & -34 & 115 \\
Derechos Totales & 4.58 & 2.525 & 2 & 14 \\
CIVLLB & 2.48 & 1.361 & 1 & 7 \\
Democracia & 17.56 & 7.452 & 0 & 31.860 \\
Graft & -0.08 & 0.780 & -1.700 & 1.550 \\
IUCN & 1.38 & 2.398 & 0 & 11.860 \\
CO2PC & 3.08 & 3.515 & 0.180 & 20.470 \\
Ecorisk & 31.49 & 33.560 & 0 & 100 \\
\hline
\end{tabular}

Fuente: Elaboración propia.

Nota: Los datos se refieren a $n=33$ países.

En cuestiones políticas, los derechos totales aparecen con un índice de 4.58 para la región y cuando se consideran los países del mundo, este indicador toma un valor de 6.73. Esto significa que, con base en el índice político de Freedom House, los derechos de los ciudadanos son menos respetados en promedio en Latinoamérica que en el resto de las regiones. Los índices de Freedom House son menores que los promedios mundiales, lo que indica que el respecto por las libertades civiles y los derechos políticos es mayor en los países de la región que en el mundo. Asimismo, si se 
considera el índice de Democracia propuesto por Vanhanen, Latinoamérica presenta un valor más favorable que el promedio mundial (17.56 versus 16.02 ).

En cuanto a indicadores relacionados con el ambiente, en promedio se emiten 3.08 toneladas de dióxido de carbono per capita en Latinoamérica, cerca de la mitad del promedio mundial (5.14 toneladas per capita). Un 31\% de los territorios tiene sus biosferas amenazadas, lo que pone en peligro de extinción a especies animales y vegetales. Por otro lado, Latinoamérica tiene 1.38 organizaciones ambientales por cada millón de habitantes, similar al promedio mundial de 1.63 .

Cuando se observan los datos para los diferentes países de la región, se verifica una gran dispersión en cuestiones de desarrollo, encontrándose países con PIB per capita que van desde 574 dólares (justamente para Haití, que también es la nación que menos cumple con la agenda ambiental internacional) hasta 17,943 (el caso de Bahamas, que es un buen cumplidor en cuanto a lo ambiental). Por su parte, Argentina aparece dentro del grupo de países con alto ingreso per capita, sin embargo su performance en cuanto al cumplimiento de los lineamientos de la Agenda 21 es escasa (26.3\%). Esta misma escena se repite en los guarismos de educación y esperanza de vida: Haití presenta los índices más desfavorables mientras que los indicadores para Argentina son de los más altos de las naciones de la región. Sin embargo, Bahamas, aunque presenta el ingreso per capita más alto, se encuentra entre los países con bajos indicadores de condiciones de vida.

En cuestiones políticas, también hay mucha disparidad con países que tienen el máximo indicador de respeto de los derechos totales (por ejemplo, Chile y Uruguay que presentan un índice de 2) y naciones como Cuba y Haití con índices de 14 y 9 , respectivamente. Si bien estas dos últimas son las que presentan menor respeto por las libertades civiles y políticas, su actitud frente a las políticas ambientales es dispar: mientras Haití es el país con menor cantidad de acuerdos ratificados y pocas estrategias ambientales en la agenda internacional, Cuba se ubica entre los países que siguen en mayor medida los lineamientos ambientales.

En cuestiones más puramente de estatus ambiental, relativamente independientes de su riqueza natural (como es el indicador de regiones con especies en peligro de extinción), se puede observar que hay países con bajas emisiones de dióxido de carbono per capita (otra vez Haití aparece en la escena, seguido Paraguay), mientras que otros, como Venezuela, Bahamas y México, muestran valores más elevados. El país que presenta las mayores emisiones per capita es Trinidad y Tobago, lo cual es congruente con los compromisos ambientales internacionales asumidos y reflejados en la ratificación de tratados. 
Resultados del estudio de relación de los determinantes de la política ambiental internacional de los países

Ahora bien, si se quiere precisar más allá de evaluaciones cualitativas entre las políticas ambientales internacionales y las variables que las determinan, se debe realizar una estimación estadística de dicha relación.

Por ello es que, primero, al seguir el espíritu de Tonn (2007), se estimaron dos modelos de regresión de mínimos cuadrados clásicos:

$$
P A_{i}=\alpha+\beta \cdot Y_{i}+\chi \cdot P_{i}+\delta \cdot X_{i}+\varepsilon_{i}
$$

Dónde $i$ se refiere a cada uno de los países de la muestra, $P A$ es uno de los dos indicadores de política ambiental internacional (ratificación de tratados y cumplimiento de la agenda 21), $Y$ son los indicadores referidos a cuestiones económicas, $P$ indica las variables referidas al régimen político y $X$ incluye a otras variables como las referidas al estatus ambiental. ${ }^{6}$

Las dos primeras columnas del cuadro 4 muestran los resultados para dos modelos. El modelo 1 intenta cuantificar cómo las variables económicas, de política y de la situación ambiental explican el número de acuerdos internacionales ratificados. El modelo 2 estima esa misma relación con el segundo indicador de política ambiental: la aplicación de las metas de la Agenda 21.

Luego de estimar los modelos 1 y 2 por una regresión de mínimos cuadrados ordinarios, puede verse en el cuadro 4 que hay dos variables significativas encontradas como predictores de la política ambiental. Éstas son el Índice de Desarrollo Humano (HDI, por sus siglas en inglés) (el cual incluye educación, esperanza de vida y un componente de ingresos) y la variable de crecimiento de la población solamente en el modelo 1. Entonces, en lo que se refiere a las naciones de la región, parecería que cuanto más desarrollado sea un país, mayor es el número de acuerdos ratificados, por lo que mejora su disposición a adoptar medidas ambientales. Mayor presión demográfica es asociada con más ratificación de tratados. Por otro lado, el HDI es también significativo y tiene el mismo signo para el cumplimiento de la Agenda 21 (modelo 2), pero surge la democracia como otra variable significativa.

6 En este trabajo, para la elección de variables dentro de cada subgrupo, se utilizó el test de factor de inflación de varianza (VIF). El valor más alto de VIF es cercano a 3, por lo que se descartan problemas de multicolinealidad.

Vol. 39, núm. 154, julio-septiembre / 2008

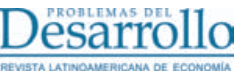


Cuadro 4

Resultados de la estimación de los modelos

\begin{tabular}{|c|c|c|c|c|}
\hline \multirow{2}{*}{$\begin{array}{l}\text { Método de estimación } \\
\text { Variables independientes }\end{array}$} & \multicolumn{2}{|c|}{ Regresión OLS } & \multicolumn{2}{|c|}{ Sistema de Ecuaciones (SUR) } \\
\hline & $\begin{array}{c}\text { Modelo } 1 \\
\text { (Ratificación) }\end{array}$ & $\begin{array}{l}\text { Modelo } 2 \\
\text { (Agenda 21) }\end{array}$ & $\begin{array}{l}\text { Modelo } 1 \\
\text { (Ratificación) }\end{array}$ & $\begin{array}{c}\text { Modelo } 2 \\
\text { (Agenda 21) }\end{array}$ \\
\hline \multirow[t]{2}{*}{ HDI } & $14.612^{* * *}$ & $196.050^{* *}$ & $14.612^{* * *}$ & $196.050^{* *}$ \\
\hline & -3.75 & -92.088 & -3.198 & -78.533 \\
\hline \multirow[t]{2}{*}{ Densidad } & -0.002 & -0.038 & -0.002 & -0.038 \\
\hline & -0.001 & -0.038 & -0.001 & -0.033 \\
\hline \multirow[t]{2}{*}{ GR2050 } & $0.020^{* * *}$ & 0.048 & $0.020^{* * *}$ & 0.048 \\
\hline & -0.007 & -0.176 & -0.006 & -0.15 \\
\hline \multirow[t]{2}{*}{ Democracia } & -0.019 & $-1.645^{* *}$ & -0.019 & $-1.645^{* *}$ \\
\hline & -0.031 & -0.76 & -0.026 & -0.648 \\
\hline \multirow[t]{2}{*}{ Graft } & -0.284 & 2.999 & -0.284 & 2.999 \\
\hline & -0.386 & -9.484 & -0.329 & -8.088 \\
\hline \multirow[t]{2}{*}{$\mathrm{CO} \mathrm{PC}$} & 0.081 & -1.187 & 0.081 & -1.187 \\
\hline & -0.059 & -1.441 & -0.05 & -1.229 \\
\hline \multirow[t]{2}{*}{ Ecorisk } & 0.005 & 0.142 & 0.005 & 0.142 \\
\hline & -0.006 & -0.156 & -0.005 & -0.133 \\
\hline \multirow[t]{2}{*}{ IUCN } & -0.096 & -1.832 & -0.096 & -1.832 \\
\hline & -0.09 & -2.207 & -0.077 & -1.882 \\
\hline \multirow[t]{2}{*}{ Constante } & -2.952 & -84.68 & -2.952 & -84.68 \\
\hline & -2.971 & -72.956 & -2.533 & -62.217 \\
\hline Número de observaciones & 33 & 33 & 33 & 33 \\
\hline$R^{2}$ & 0.589 & 0.335 & 0.589 & 0.335 \\
\hline
\end{tabular}

Fuente: Elaboración propia.

Nota: $*, * * *$ indican un nivel de significatividad de $10 \%$ y $1 \%$ respectivamente. Los errores estándar se muestran entre paréntesis. En cada una de las regresiones OLS se realizó el test de error de especificación propuesto por Ramsey, Regresión Specification Error Test (RESET), obteniéndose un p-value de 0.33 para el modelo 1 y 0.69 para el modelo 2 , por lo que los modelos parecen no presentar errores de especificación.

El signo es negativo, por lo que más democracia está asociada con menor cumplimiento con los medios disponibles para cumplir con la Agenda $21 .^{7}$

Pero también es cierto que el hacer dos regresiones separadas implica suponer que las dos variables a explicar (ratificación de tratados y alcanzar las metas de la Agenda

7 Para descartar que el resultado de la variable democracia en la regresión de Agenda 21 no se deba a la presencia de outliers, se analizaron los residuos estandarizados de la regresión (residuos transformados con media cero y desvío igual a uno) así como el leverage. Surge que Barbados es un país cuyos datos tienen gran influencia en las estimaciones (única nación donde se verifican altos residuos estandarizados y alto leverage). Pero al analizar a detalle el impacto sobre las variables de la regresión, se observa que los coeficientes de condiciones de vida son los que aumentan de manera significativa (1.20 errores estándar del coeficiente HDI y 2.06 errores estándar del coeficiente de densidad), mientras que si se excluye Barbados, el coeficiente de democracia sólo disminuirá 0.44 errores estándar. 
21) son independientes. Podría pasar que el número de tratados ratificados se relacione con un mayor o menor compromiso en relación con la Agenda 21 y viceversa. Para comprobar la posible endogenidad de las variables dependientes se aplicó el test de Hausman a los modelos anteriores. ${ }^{8}$ El resultado indica que los coeficientes de las regresiones de mínimos cuadrados ordinarios (OLS, por sus siglas en inglés) son consistentes de manera significativa. El modelo parece no involucrar la simultaneidad de las variables endógenas.

Sin embargo, podría darse el caso que algunas variables no controladas en las dos regresiones expliquen ambas variables dependientes. Es decir, puede ocurrir que exista algún factor no considerado que afecte tanto a la variable de tratados como a la de la Agenda 21, del cual no se tengan datos (por ejemplo, la presión internacional mencionada más arriba). Para controlar esa posibilidad, se procedió a la estimación de un modelo de regresiones que aparentemente no están relacionadas (SUR, por sus siglas en inglés). Pero previamente a la aplicación del método SUR se hizo una prueba de la correlación contemporánea entre los términos de error de ambas ecuaciones. La hipótesis nula para esta prueba es $H_{0}: \sigma_{12}=0$. El estadístico utilizado es el propuesto por Breusch y Pagan:

$$
N \cdot r_{12}^{2} \sim \chi_{(1)}^{2}
$$

dónde es el cuadrado del coeficiente de correlación contemporáneo calculado como:

$$
r_{12}^{2}=\frac{\left(\widehat{\sigma}_{12}\right)^{2}}{\hat{\sigma}_{1}^{2} \cdot \widehat{\sigma}_{2}^{2}}
$$

Si la correlación es alta, la ganancia en eficiencia (variancia mínima) por aplicar el método SUR en lugar de OLS resulta importante. En este caso, el valor del estadístico

8 En rigor, para contrastar la sospecha de endogenidad se efectuaron dos pruebas: por un lado, el test de Hausman (1978) que compara las estimaciones OLS con las estimaciones OLS en dos etapas (2SLS, por sus siglas en inglés) con uso de variables instrumentales y determina si las diferencias son estadísticamente significativas. También se efectuó el test de regresión propuesto por Wooldridge (2002). Para ello se regresó la variable que se sospecha endógena sobre un conjunto de variables exógenas y se obtuvo el residuo de la estimación. Luego se regresó el modelo original incluyendo los residuos estimados resultando no significativo. Se propuso como variables instrumentales a las variables seleccionadas para las regresiones del cuadro 4 y un indicador de eficiencia gubernamental propuesto por el Banco Mundial, Goveff (véase Anexo B). La idea es que el nivel de eficiencia gubernamental repercute en la manera que tienen los países de responder a cuestiones ambientales. Se verifica que los niveles de eficiencia ejercen una influencia positiva significativa sobre la aplicación de acuerdos internacionales (correlación positiva entre instrumento y variable aplicada). 
para los datos es 5,412 con un valor $p$ de 0.020 , por lo que se rechaza la hipótesis nula de independencia de residuos entre las ecuaciones de Ratificación de tratados y Agenda 21 con 5\% de significancia. Así, el método de estimación SUR parece ser más apropiado que OLS. ${ }^{9}$

Los resultados de esta nueva estimación se reportan en las dos últimas columnas del cuadro 4. Se reafirma la hipótesis de que a mayor desarrollo humano (incluye educación, esperanza de vida y un componente de ingresos) en los países de la región, mayor es la cantidad de tratados ratificados y, por ende, mayor preocupación por el futuro ambiental. Ello es razonable pues indica que a un mayor nivel de vida, son más las demandas ambientales y mejores las tecnologías.

Asimismo, el crecimiento de la población también parece tener influencia en la adopción de políticas ambientales. A mayor presión demográfica, menor disponibilidad de recursos naturales per capita, lo que alienta a una mayor preocupación por el cuidado ambiental.

Se confirma que el respeto por los derechos políticos y civiles en una sociedad democrática no es un factor determinante para tener políticas ambientales activas. El signo negativo de los coeficientes estimados estaría indicando que cuanto menos democrática sea una sociedad, su preocupación por el tema ambiental sería mayor. ${ }^{10} \mathrm{La}$ variable corrupción no es significativa en nuestros modelos, y es sensible al indicador utilizado. A menos corrupción menos tratados son ratificados, pero sí se toman más acciones en favor de la Agenda 21.

9 También se comprobó la hipótesis de normalidad de los residuos. En efecto, la normalidad de los residuos no es requisito para hacer inferencia en muestras grandes, pero sí lo es para muestras chicas (como ésta). Como en general la causa de la no normalidad de los errores es la no normalidad de la distribución de las variables independientes y/o dependientes, lo estándar es revisar la normalidad de los residuos. Si éstos no son normales, entonces se analiza la distribución de variables del modelo y se examina si, a partir de alguna transformación, se logra que adopten una distribución similar a la normal, y si tal transformación repercute en la distribución de los errores (Greene, 2000). Por ello, realizamos el test de Shapiro-Wilk sobre los residuos de cada especificación SUR. Los estadísticos W toman valores entre 0.973 y 0.987 con un p value superior a 0.57 en todos los casos, con lo cual concluimos que no existe evidencia suficiente para rechazar la hipótesis nula de normalidad de los errores. De esta manera la inferencia es válida y no necesitamos trasformar variables para lograr normalidad de los residuos.

10 A pedido de uno de los árbitros se probó incorporar a la estimación una variable que discrimina si el sistema político es presidencialista o no. Al hacerlo, se refuerzan los resultados anteriores. Es decir, las variables de política (democracia y presidencial) siguen siendo no significativas para Ratificación, y son ambas significativas para Agenda 21 (democracia sigue con signo negativo y presidencial con signo positivo, indicando que no sólo el ser un país democrático tiene influencia). 
El estatus ambiental parece no determinar la aplicación de políticas ambientales. La variable de emisiones de carbono per capita presenta signos opuestos de un modelo a otro, mientras que la variable de especies en peligro de extinción presenta una relación positiva con la preocupación por el cuidado ambiental. Pero ninguna de las dos medidas de la situación ambiental y de recursos naturales de los países tiene un impacto significativo ni en el modelo de tratados ni en el de cumplimiento de la Agenda 21. La presencia de organizaciones ambientales, si bien es citada por lo general como factor de presión a la adopción de políticas ambientales, tampoco parece tener influencia significativa en la adopción de las mismas en la región.

También puede observarse en el cuadro 4 que no hay grandes diferencias en la significatividad de los coeficientes por el uso de un sistema de ecuaciones, aunque algo mejora la significatividad de algunas de las variables (pero son las mismas las que son significativas).

Para confirmar la robustez de nuestros resultados, probamos algunas variantes en nuestras estimaciones, las cuales son reportadas en el cuadro 5. En primer lugar (Sistemas de Ecuaciones I), introdujimos el PIB per capita como variable explicativa sobre la manera de controlar con la riqueza, explícitamente, por fuera del índice de desarrollo. Como puede observarse, los resultados se mantienen similares y el PIB per capita no resulta significativo en ninguna de las ecuaciones, aunque sí tuvo el signo positivo esperado. ${ }^{11}$ Debido a ello, introdujimos los componentes del índice HDI de forma separada para verificar si alguno de ellos tenía más influencia que los demás (es decir, que pudiera ser la educación más que el PIB —ambos representados en el indicador de desarrollo HDI- el determinante de las políticas ambientales). El resultado de este Sistema de Ecuaciones II fue que educación y esperanza de vida son significativas para ratificar tratados pero no lo es el PIB, mientras que ninguna de las tres variables que componen el índice de HDI continúa siendo significativa para aplicar medidas de la Agenda 21. Ello estaría indicando que es un tema de desarrollo

11 A su vez, se corrieron los modelos al incorporar el cuadrado del PIB per capita para analizar la posible relación no lineal con las variables de ambiente. Tanto el PIB como su cuadrado fueron expresados en forma de desviación para reducir problemas de multicolinealidad. Sólo el modelo de ratificación de tratados presenta una relación cuadrática con el ingreso per capita, aunque el estadístico z (1.67) es muy próximo a su valor crítico a 5\%. Por otro lado, la constante aparece significativa. Si a esto se le suma el hecho de que el problema de correlación entre el ingreso y su cuadrado — si bien se reduce sustancialmente con la transformación de las variables en términos de desvíos - puede persistir, no queda del todo claro que la relación sea cuadrática. Por último, se incorporó el ingreso per capita expresado en logaritmos como es usual encontrarlo en la literatura de la U de Kuznets, pero tampoco se verifica ninguna relación significativa con las variables de cuidado ambiental.

Vol. 39, núm. 154, julio-septiembre / 2008 
y no de riqueza lo que conduce a compromisos ambientales internacionales. Las variables políticas, de crecimiento poblacional y de estatus ambiental no cambian de signo y se mantiene la significatividad.

Un segundo test de robustez consistió en utilizar como variables políticas dos que fueron publicadas por Freedom House: el total de derechos civiles y políticos (Sistema de Ecuaciones III) y el promedio de dichos derechos (Sistema de Ecuaciones IV). Como resultado de estas variantes, las variables políticas son nuevamente significativas (con excepción del promedio de derechos), y a menor protección de los derechos civiles y políticos de los ciudadanos, la política ambiental internacional es más activa. El HDI y el crecimiento de la población se mantienen significativas y con el mismo signo.

Cuadro 5

Análisis de sensibilidad de especificaciones alternativas

\begin{tabular}{|c|c|c|c|c|c|c|c|c|}
\hline \multirow{2}{*}{$\begin{array}{l}\text { Método de estimación } \\
\text { Variables independientes }\end{array}$} & \multicolumn{2}{|c|}{ Sistema de Ecuaciones (I) } & \multicolumn{2}{|c|}{ Sistema de Ecuaciones (II) } & \multicolumn{2}{|c|}{ Sistema de Ecuaciones (III) } & \multicolumn{2}{|c|}{ Sistema de Ecuaciones (IV) } \\
\hline & $\begin{array}{l}\text { Modelo 1 } \\
\text { (Ratificación) }\end{array}$ & $\begin{array}{c}\text { Modelo } 2 \\
\text { (Agenda 21) }\end{array}$ & $\begin{array}{l}\text { Modelo I } \\
\text { (Ratificación) }\end{array}$ & $\begin{array}{c}\text { Modelo } 2 \\
\text { (Agenda 21) }\end{array}$ & $\begin{array}{l}\text { Modelo } 1 \\
\text { (Ratificación) }\end{array}$ & $\begin{array}{c}\text { Modelo } 2 \\
\text { (Agenda 21) }\end{array}$ & $\begin{array}{l}\text { Modelo } 1 \\
\text { (Ratificación) }\end{array}$ & $\begin{array}{c}\text { Modelo } 2 \\
\text { (Agenda 21) }\end{array}$ \\
\hline HDI & $\begin{array}{l}14.568^{* * *} \\
-3.298\end{array}$ & $\begin{array}{l}191.971^{* *} \\
-80.946\end{array}$ & & & $\begin{array}{l}14.646 * * * \\
-3.107\end{array}$ & $\begin{array}{l}185.139 * * \\
-77.153\end{array}$ & $\begin{array}{l}14.414^{* * *} \\
-3.194\end{array}$ & $\begin{array}{l}179.630 * * \\
-82.249\end{array}$ \\
\hline PIB per capita & $\begin{array}{r}0.000 \\
0\end{array}$ & $\begin{array}{r}0.000 \\
-0.002\end{array}$ & $\begin{array}{r}0,000 \\
0\end{array}$ & $\begin{array}{r}0.001 \\
-0.002\end{array}$ & & & & \\
\hline Vidax & & & $\begin{array}{l}6.132^{* *} \\
-2,634\end{array}$ & $\begin{array}{r}88.073 \\
-70.369\end{array}$ & & & & \\
\hline Edux & & & $\begin{array}{l}7.237^{* * *} \\
-2,653\end{array}$ & $\begin{array}{r}80.880 \\
-70.871\end{array}$ & & & & \\
\hline lensidad & $\begin{array}{l}-0.002 \\
-0.001\end{array}$ & $\begin{array}{l}-0.039 \\
-0.033\end{array}$ & $\begin{array}{l}-0.001 \\
-0.001\end{array}$ & $\begin{array}{l}-0.034 \\
-0.033\end{array}$ & $\begin{array}{l}-0.001 \\
-0.001\end{array}$ & $\begin{array}{r}-0.001 \\
-0.03\end{array}$ & $\begin{array}{l}-0.002 \\
-0.001\end{array}$ & $\begin{array}{l}-0.008 \\
-0.032\end{array}$ \\
\hline GR2050 & $\begin{array}{l}0.020^{* * *} \\
-0.006\end{array}$ & $\begin{array}{r}0.039 \\
-0.156\end{array}$ & $\begin{array}{l}0.021^{* * *} \\
-0.006\end{array}$ & $\begin{array}{r}0.040 \\
-0.162\end{array}$ & $\begin{array}{l}0.022^{* * *} \\
-0.006\end{array}$ & $\begin{array}{l}0.147 \\
-0.15\end{array}$ & $\begin{array}{l}0.020^{* * *} \\
-0.006\end{array}$ & $\begin{array}{r}0.083 \\
-0.158\end{array}$ \\
\hline Democra & $\begin{array}{l}-0.019 \\
-0.027\end{array}$ & $\begin{array}{l}-1.628^{* *} \\
-0.653\end{array}$ & $\begin{array}{l}-0.014 \\
-0.024\end{array}$ & $\begin{array}{c}-1.547^{* *} \\
-0.64\end{array}$ & & & & \\
\hline Derechos Totales & & & & & $\begin{array}{r}0.122 \\
-0.085\end{array}$ & $\begin{array}{l}5.713^{* * *} \\
-2.107\end{array}$ & & \\
\hline IVLLB & & & & & & & $\begin{array}{r}0.070 \\
-0.159\end{array}$ & $\begin{array}{r}6.537 \\
-4.106\end{array}$ \\
\hline Graft & $\begin{array}{l}-0.297 \\
-0.401\end{array}$ & $\begin{array}{r}1.843 \\
-9.845\end{array}$ & $\begin{array}{l}-0.310 \\
-0.371\end{array}$ & $\begin{array}{r}1.534 \\
-9.901\end{array}$ & $\begin{array}{r}-0.116 \\
-0.35\end{array}$ & $\begin{array}{r}8.505 \\
-8.692\end{array}$ & $\begin{array}{l}-0.287 \\
-0.347\end{array}$ & $\begin{array}{l}3.210 \\
-8.93\end{array}$ \\
\hline $\mathrm{CO} 2 \mathrm{PC}$ & $\begin{array}{r}0.078 \\
-0.073\end{array}$ & $\begin{array}{l}-1.453 \\
-1.782\end{array}$ & $\begin{array}{r}0.062 \\
-0.066\end{array}$ & $\begin{array}{l}-1.677 \\
-1.755\end{array}$ & $\begin{array}{r}0.079 \\
-0.049\end{array}$ & $\begin{array}{l}-1.207 \\
-1.215\end{array}$ & $\begin{array}{r}0.079 \\
-0.051\end{array}$ & $\begin{array}{r}-1.382 \\
-1.31\end{array}$ \\
\hline Ecorisk & $\begin{array}{r}0.005 \\
-0.006\end{array}$ & $\begin{array}{r}0.147 \\
-0.136\end{array}$ & $\begin{array}{r}0.004 \\
-0.005\end{array}$ & $\begin{array}{l}0.136 \\
-0.14\end{array}$ & $\begin{array}{r}0.003 \\
-0.006\end{array}$ & $\begin{array}{r}0.057 \\
-0.137\end{array}$ & $\begin{array}{r}0.005 \\
-0.006\end{array}$ & $\begin{array}{r}0.098 \\
-0.146\end{array}$ \\
\hline IUCN & $\begin{array}{l}-0.095 \\
-0.077\end{array}$ & $\begin{array}{l}-1.774 \\
-1.901\end{array}$ & $\begin{array}{r}-0.100 \\
-0.07\end{array}$ & $\begin{array}{l}-1.821 \\
-1.871\end{array}$ & $\begin{array}{l}-0.075 \\
-0.075\end{array}$ & $\begin{array}{l}-0.625 \\
-1.871\end{array}$ & $\begin{array}{l}-0.083 \\
-0.078\end{array}$ & $\begin{array}{r}-0.661 \\
-2.02\end{array}$ \\
\hline Constante & $\begin{array}{l}-2.935 \\
-2.553 \\
\end{array}$ & $\begin{array}{l}-83.087 \\
-62.658 \\
\end{array}$ & $\begin{array}{l}-2.985 \\
-2.055\end{array}$ & $\begin{array}{l}-76.690 \\
-54.909 \\
\end{array}$ & $\begin{array}{r}-3.947 \\
-2.53 \\
\end{array}$ & $\begin{array}{c}-138.495^{* *} \\
-62.824 \\
\end{array}$ & $\begin{array}{l}-3.364 \\
-2.588 \\
\end{array}$ & $\begin{array}{c}-121.936^{*} \\
-66.648 \\
\end{array}$ \\
\hline Número & 33 & 33 & 33 & 33 & 33 & 33 & 33 & 33 \\
\hline$R^{2}$ & 0.589 & 0.335 & 0.666 & 0.359 & 0.607 & 0.35 & 0.585 & 0.261 \\
\hline
\end{tabular}

Fuente: Elaboración propia.

Nota: ${ }^{*}, * *$ indican un nivel de significatividad de $10 \%$ y $1 \%$ respectivamente.

Los errores estándar se muestran entre paréntesis.

\section{Desaarrollo}




\section{Conclusiones}

Este trabajo intenta evaluar los predictores de la adopción de políticas ambientales por parte de los países de la región de América Latina y el Caribe. Para ello adopta dos indicadores de política ambiental internacional: el número de tratados ratificados por las naciones de los tratados más importantes sobre temas ambientales internacionales, así como porcentaje de cumplimiento de las 19 metas de la Agenda 21. Se consideran distintas variables explicativas alternativas relacionadas con tres temas centrales: variables económicas, de política y de la situación ambiental de los países.

Las técnicas utilizadas para el análisis de los determinantes de los dos indicadores ambientales son, en primer lugar, la estimación de dos ecuaciones independientes (una para tratados y la otra para Agenda 21) por medio del tradicional método de los mínimos cuadrados ordinarios. Luego de comprobar que se cumplen todas las hipótesis necesarias para que los resultados obtenidos tengan validez, se hace una estimación de un sistema de dos ecuaciones relacionadas. Este método permite que se capture la influencia que puedan tener variables no observables (por ejemplo, la presión internacional hacia la adopción de políticas ambientales activas) que afectan al mismo tiempo la firma de tratados y el cumplimiento de la Agenda 21.

Las únicas variables que parecen ser importantes — para evaluar si los países de la región de América Latina y el Caribe van a adoptar políticas más activas en favor de la conservación del ambiente- parecen ser el grado de desarrollo humano (que mide educación, esperanza de vida y PIB) y la presión demográfica en uno de los modelos. El hecho de que los países latinoamericanos sean más o menos democráticos y respeten más los derechos de sus ciudadanos no tiene el impacto esperado sobre su compromiso hacia el ambiente. Es decir, no se daría el efecto de que las democracias como tienen una visión de más largo plazo (los gobiernos democráticos temen menos ser desplazados ya que fueron elegidos por el voto popular) atienden más los problemas del futuro, ni que más libertad de prensa, de opinión, de asociación y de voto de sus representantes llevan a mayor cuidado del ambiente. Por el contrario, podría darse el caso de que los gobiernos más democráticos, como dependen del voto popular, son más dependientes del logro del desarrollo económico (más que del ambiental) para mantenerse en el poder. Por ende, tenderían a dar menos prioridad a este último y más al primero.

Los resultados son robustos a distintas especificaciones empíricas. Además, al separar el Índice de Desarrollo Humano en sus distintos componentes, puede observarse que la aplicación de medidas locales concretas del cuidado del ambiente no mantiene relación exclusivamente con los mayores niveles de PIB per capita en 
la región como suele creerse. Cuestiones como que la población sea más educada, resulta importante como determinante de la preocupación de un país por un futuro sustentable.

Las relaciones encontradas deberían confirmarse en futuros estudios. En efecto, los mismos se basan en una base de datos de sección cruzada de unos pocos países, ya que el análisis se focaliza en una región particular, no en todas las naciones del mundo. Por ello, el número de observaciones es reducido. Mejorar sobre esa situación requiere armar un panel de observaciones en el tiempo para los distintos países. Ello, aunque factible, no era el objetivo de este primer trabajo sobre esta temática. Sin embargo, la calidad de los datos utilizados es buena ya que se trata en todos los casos de fuentes internacionales homogéneas con verificaciones serias de los datos. En cuanto a la metodología utilizada, si bien los resultados no son muy diferentes a los obtenidos con la metodología tradicional de mínimos cuadrados ordinarios, la utilización del método SUR para las estimaciones es un avance respecto de la literatura empírica en esta área. Además se han llevado a cabo los tests estándar de multicolinealidad, normalidad de los residuos, endogenidad, etcétera, para garantizar la calidad de los resultados. También se comprobó la robustez de los hallazgos con diferentes análisis de sensibilidad e incorporando variables económicas y políticas alternativas.

Aunque debe hacerse más trabajo para ampliar el número de observaciones, este artículo pretende ser un paso hacia una explicación del porqué de las diferencias de las políticas ambientales entre los distintos países de América Latina y el Caribe. Parecería ser una particularidad de la región que naciones menos democráticas tiendan a tener políticas ambientales más activas. Lo que podría estar sucediendo en realidad es que son los gobiernos más centralizados los que piensan más en planificar el uso del ambiente, mientras que los gobiernos más democráticos (con aún poca presión de sus ciudadanos hacia un ambiente más limpio) prefieren otros objetivos por sobre los ambientales. Seguramente tienen alta prioridad en estos objetivos el mantener la estabilidad económica y promover el crecimiento. 


\section{Bibliografía}

Agencia Central de Inteligencia, The World Factbook, www.cia.gov/cia/publications/ factbook, último ingreso 13 de mayo de 2008.

Banco Mundial, Health, Nutrition and Population Statistics, http://devdata.worldbank. org/hnpstats/, último ingreso 13 de mayo de 2008.

Barrett, Scott y Kathryn Grady, "Freedom, growth and the environment", en Environment and Development Economics, vol. 5 , núm 4, Cambridge, Cambridge University Press, octubre 2000, pp. 433-456.

Barros Vicente y Mariana Conte Grand, "The Meaning of a Dynamic Target of GHG emissions reduction: the case of Argentina", Environment and Development Economics, vol. 7, núm. 3, Cambridge, Cambridge University Press, julio 2002, pp. 547-569.

Centro para la Red Internacional de Ciencias de la Tierra, 2005 Environmental Sustainability Index, http://sedac.ciesin.columbia.edu/ es/esi, último ingreso 13 de mayo de 2008.

Congleton, Roger D, "Political institutions and pollution control", en Review of Economics and Statistics, vol. 74, núm. 3, MIT Press, agosto 1992, pp. 412-421.

Dasgupta, Susmita, et al., "Confronting the Environmental Kuznets Curve", Journal of Economic Perspectives, vol. 16, American Economic Association, invierno 2002, pp. 147-168.

Esty, Daniel C. y Michael E. Porter, "Ranking National Environmental Regulation and Performance: A Leading Indicator of Future Competitiveness?" en Michael E. Porter, Jeffry D. Sachs, y Klaus Schab (eds.), The Global Competitiveness Report 2001-2002, Nueva York, Oxford University Press, 2002.

Farzin, Y. Hossein y Craig A. Bond, "Democracy and Environmental Quality", Journal of Development Economics, vol. 81, núm 1, Elsevier, octubre 2006, pp. 213-35.

Fredriksson, Per G. y Jim R. Wollscheid, "Democratic Institutions versus Autocratic Regimes: The Case of Environmental Policy", Public Choice, vol. 130, núm. 3-4, Springer Netherlands, 2007, pp. 381-93.

Freedom House, Ratings de libertad mundiales, www.freedomhouse.org, último ingreso 13 de mayo de 2008.
Greene, William H., Econometric Analysis, 4a edición, Nueva York, Prentice Hall, 2000.

Grossman, Gene M., y Alan B. Krueger, "Economic Growth and the Environment", The Quarterly Journal of Economics, vol. 110, núm. 2, MIT Press, mayo 1995, pp. 353-378.

Harbaugh, William T., et al., "Reexamining the empirical evidence for an environmental Kuznets curve", Review of Economics and Statistics, vol. 84, núm. 3, MIT Press, agosto 2002 , pp. 541-551.

Instituto de Recursos Mundiales, Tablas de Tendencias Mundiales: Biodiversidad y Áreas protegidas, www.earthtrend.wri.org/ pdf_library/data tables/bio1 2005.pdf, último ingreso 13 de mayo de 2008.

Kuznets, Simon, "Economic growth and inequality", The American Economic Review American Economic Association, vol. XLV, núm. 1, marzo 1995, pp. 1-28.

Midlarsky, Manus I., "Democracy and the Environment: an empirical assessment", Jour nal of Peace and Research, vol. 35, núm 3, mayo de 1998, pp. 341-61.

Neumayer, Eric, "Do democracies exhibit stronger international environmental commitment? A cross-country analysis", $\mathrm{JO}_{\mathrm{O}}$ urnal of Peace Research, vol. 39, núm 2, Londres, Sage Publications, marzo 2002. pp. 139-64.

Pellegrini, Lorenzo y Reyer Gerlagh, "Corruption, Democracy and Environmental Policy: An Empirical Contribution to the Debate", The Journal of Environment \& Development, vol. 15, núm. 3, Londres, Sage Publications, septiembre de 2006, pp. 332-354.

Polity Index, http://www.systemicpeace.org/ polity/polity $4 . h t m$, último ingreso $13 \mathrm{de}$ mayo de 2008.

Programa de Desarrollo de las Naciones Unidas, Reporte de Desarrollo Humano, http:// hdr.undp.org/reports/global/2005, Último ingreso 13 de mayo de 2008.

Scruggs, Lyle A., "Political and economic inequality and the environment", Ecological Economics, vol. 26, núm 3, Elsevier, septiembre 1998, pp. 259-275.

Tonn, Bruce E., "Determinants of futures-oriented environmental policies: a multi-country analysis", Futures, Elsevier, vol. 39, núm. 9, noviembre 2007, pp. 773-789. 
United Nations, Johannesburg Summit 2002National Implementation Agenda 21: A Report, Nueva York, agosto 2002, www. un.org/esa/agenda21/natlinfo/wssd/NIA_ REPORT.pdf, último ingreso 13 de mayo de 2008.

Vanhanen, Tatu, The polyarchy dataset: Vahanen's index of democracy, http://new. prio.no/CSCW-Datasets/Data-on-Gover-
nance/The-Polyarchy-dataset/, último ingreso 13 de mayo de 2008.

Wikipedia, Lista de países según sistema de gobierno, www.wikipedia.org/wiki/List_ of_countries_by_system_of_government, último ingreso 13 de mayo de 2008.

Wooldridge, Jeffrey M., Econometric Analysis of Cross Section and Panel Data, Cambridge, MIT Press, 2002.

\section{Anexo A. Variables de política ambiental internacional}

\begin{tabular}{ll}
\hline \multicolumn{1}{c}{ Acuerdos internacionales considerados } & \multicolumn{1}{c}{ Medios para cumplimentar la Agenda 21} \\
\hline 1. Convención de biodiversidad & 1. Programa sobre Indicadores de Desarrollo Sustentable \\
2. Protocolo de Bioseguridad & 2. Programa de Eco-etiquetado \\
3. Convención sobre el Cambio Climático & 3. Campaña de Ahorro Energético Orientado a los Consumidores \\
4. Protocolo de Kyoto & 4. Estadísticas Nacionales de Transporte \\
5. Convención sobre Desertificación & 5. Sistema de Inventario de Emisiones de Gas \\
6. Convención de Comercio Internacional de Especies en Peligro & 6. Sistema de Información Geográfica para la Administración de \\
7. Protocolo de Montreal & las Tierras \\
8. Convención de Basilea & 7. Programa de Indicadores Forestales \\
9. Ley de los Mares & 8. Inventarios Forestales \\
10. Convención sobre los Humedales & 9. Monitoreo Forestal \\
11. Convención de Pueblos Indígenas & 10. Monitoreo de Desertificación \\
& 11. Monitoreo de Montañas \\
12. Bases de datos sobre Suelos \& tierras (Agricultura) & 13. Inventario de Especies \\
14. Monitoreo de Biodiversidad \\
15. Monitoreo de Recursos Marinos \\
16. Monitoreo de Calidad del Agua \\
17. Base de datos sobre Químicos Tóxicos \\
18. Base nacional de datos sobre Residuos \\
19. Contaminación \& Monitoreo de su Tratamiento Monitoreo \\
\hline
\end{tabular}

Fuente: Elaboración propia con base en UN (2002).

\section{Desarrrollo}


Anexo B. Determinantes de la política ambiental para América Latina y el Caribe

\begin{tabular}{|c|c|c|c|c|c|c|c|c|}
\hline País & Rat & Agenda21 & HDI & $\begin{array}{l}\text { PIB per capita } \\
\text { (U\$S) }\end{array}$ & PIBX & Vidax & Educx & Densidad \\
\hline Antigua y Barbuda & 8 & 5.26 & 0.808 & 11,506 & 0.81 & 0.82 & 0.8 & 190 \\
\hline Arrentina & 10 & 26.32 & 0.863 & 5,472 & 0.82 & 0.83 & 0.95 & 14 \\
\hline Bahamas & 9 & 47.37 & 0.825 & 17,943 & 0.87 & 0.75 & 0.86 & 33 \\
\hline Barbados & 9 & 73.68 & 0.879 & 11,446 & 0.84 & 0.84 & 0.96 & 628 \\
\hline Belice & 8 & 0 & 0.751 & 4,094 & 0.7 & 0.78 & 0.77 & 13 \\
\hline Bolivia & 11 & 36.84 & 0.692 & 1,195 & 0.55 & 0.66 & 0.87 & 9 \\
\hline Brasil & 10 & 57.89 & 0.792 & 5,660 & 0.74 & 0.76 & 0.88 & 22 \\
\hline Chile & 9 & 68.42 & 0.869 & 8,865 & 0.78 & 0.89 & 0.91 & 22 \\
\hline Colombia & 9 & 63.16 & 0.79 & 2,982 & 0.7 & 0.7 & 0.86 & 41 \\
\hline $\begin{array}{l}\text { Costa Rica } \\
\text { Con }\end{array}$ & 10 & 6667 & 0.841 & 5,047 & 0.7 & 0.8 & 0.87 & 86 \\
\hline Cuba & 10 & 73.68 & 0.826 & 4,159 & 0.67 & 0.88 & 0.93 & 103 \\
\hline Dominica & 8 & 0 & 0.793 & 4,144 & 0.6 & 0.8 & 0.86 & 97 \\
\hline Ecuador & 10 & 31.58 & 0.765 & 3,042 & 0.6 & 0.8 & 0.86 & 48 \\
\hline El Salvador & 8 & 47.37 & 0.729 & 2,618 & 0.6 & 0.77 & 0.76 & 337 \\
\hline Grenada & 7 & 0 & 0.762 & 4,799 & 0.73 & 0.67 & 0.88 & 318 \\
\hline Guatemala & 10 & 0 & 0.673 & 2,735 & 0. & 0.7 & 0.68 & 119 \\
\hline Guyana & 7 & 36.84 & 0.725 & 1,193 & 0.6 & 0.6 & 0.9 & 4 \\
\hline Haití & 5 & 10.53 & 0.482 & 574 & 0.4 & 0.45 & 0.5 & 314 \\
\hline Honduras & 10 & 52.63 & 0.683 & 1,256 & 0. & 0.7 & 0.77 & 66 \\
\hline Jamaica & 9 & 21.05 & 0.724 & 3,954 & 0.6 & 0.7 & 0.79 & 246 \\
\hline México & 11 & 84.21 & 0.821 & 8,052 & 0.77 & 0.84 & 0.86 & 55 \\
\hline Nicaragua & 10 & 61.11 & 0.698 & 1,023 & 0.6 & 0.75 & 0.75 & 43 \\
\hline Panamá & 10 & 26.32 & 0.809 & 5,205 & 0.7 & 0.83 & 0.88 & 44 \\
\hline Paraquay & 10 & 35.29 & 0.757 & 1,514 & 0.6 & 0.7 & 0.86 & 15 \\
\hline Perú & 9 & 31.58 & 0.767 & 3288 & 0.6 & 0.75 & 0.87 & 22 \\
\hline República Dominicar & 7 & 10.53 & 0.751 & 3,181 & 0.7 & 0.71 & 0.83 & 199 \\
\hline San Cristóbal y Nieves & 8 & 0 & 0.825 & 10,063 & 0.8 & 0.75 & 0.92 & 134 \\
\hline Santa Lucía & 8 & 21.05 & 0.79 & 5,457 & 0.69 & 0.79 & 0.89 & 272 \\
\hline San Vicente y las Granadinas & 7 & 0 & 0.759 & 3,895 & 0.6 & 0.77 & 0.81 & 307 \\
\hline Suriname & 7 & 26.32 & 0.759 & 3,537 & 0. & 0.74 & 0.84 & 3 \\
\hline Trinidad \& Tobago & 10 & 0 & 0.809 & 15,214 & 0.8 & 0.75 & 0.88 & 255 \\
\hline Uruquay & 9 & 10.53 & 0.851 & 5,828 & 0.76 & 0.84 & 0.95 & 19 \\
\hline Venezuela & 9 & 57.89 & 0.784 & 6,730 & 0.68 & 0.8 & 0.87 & 30 \\
\hline Promedio & 8.85 & 32.85 & 0.77 & 5,323 & 0.70 & 0.77 & 0.84 & 124.48 \\
\hline
\end{tabular}

Fuente: Elaboración propia 
MARIANA CONTE GRAND Y VANESA D’ELIA

$134>\ldots \ldots \ldots \ldots \ldots \ldots \ldots \ldots \ldots \ldots$

\begin{tabular}{|c|c|c|c|c|c|c|c|c|}
\hline País & $\begin{array}{l}\text { Derechos } \\
\text { Totales }\end{array}$ & Democracia & CIVLIB & Graft & Goveff & IUCN & $\mathrm{CO} P \mathrm{PC}$ & Ecorisk \\
\hline Antigua y Barbuda & 4 & 24.41 & 3 & 0.84 & 0.56 & 0 & 4.91 & 0 \\
\hline Argentina & 4 & 26.13 & 3 & -0.77 & -0.49 & 0 & 3.73 & 39.07 \\
\hline Bahamas & 2 & 17.38 & 1 & 1.41 & 1.4 & 3 & 5.93 & 0 \\
\hline Barbados & 2 & 10.18 & 1 & 1.29 & 1.36 & 4 & 4.4 & 0 \\
\hline Belice & 3 & 13.85 & 1.5 & -0.25 & -0.06 & 12 & 3.25 & 0.01 \\
\hline Bolivia & 6 & 20.63 & 2.5 & -0.82 & -0.53 & 1 & 1.33 & 0.55 \\
\hline Brasil & 4 & 27.4 & 2.5 & -0.05 & -0.22 & 0 & 1.79 & 51.69 \\
\hline Chile & 2 & 23.15 & 1.5 & 1.55 & 1.19 & 0 & 3.91 & 20.75 \\
\hline Colombia & 6 & 16.45 & 4 & -0.47 & -0.39 & 0 & 1.39 & 30.19 \\
\hline Costa Rica & 2 & 22.03 & 1.5 & 0.88 & 0.37 & 4 & 1.38 & 47.71 \\
\hline Cuba & 14 & 0 & 7 & -0.13 & -0.26 & 0 & 2.76 & 86.1 \\
\hline Dominica & 2 & 29.23 & 1 & 0.52 & 0.32 & 0 & 1.32 & 0 \\
\hline Ecuador & 6 & 14.17 & 3 & -1.02 & -0.96 & 2 & 2.05 & 36.1 \\
\hline El Salvador & 5 & 9.72 & 2.5 & -0.54 & -0.53 & 1 & 1.07 & 95.14 \\
\hline Grenada & 3 & 16.19 & 1.5 & 0.71 & 0.38 & 0 & 2.63 & 0 \\
\hline Guatemala & 7 & 5.49 & 4 & -0.71 & -0.61 & 1 & 0.87 & 49.3 \\
\hline Guyana & 5 & 19.59 & 2 & -0.5 & -0.32 & 0 & 2.11 & 0 \\
\hline Haití & 9 & 2.9 & 6 & -1.7 & -1.56 & 0 & 0.18 & 63.62 \\
\hline Honduras & 6 & 15.17 & 3 & -0.78 & -0.73 & 1 & 0.74 & 87.27 \\
\hline Jamaica & 5 & 12.46 & 2.5 & -0.46 & -0.07 & 2 & 4.18 & 75.76 \\
\hline México & 5 & 20.78 & 2 & -0.19 & 0.15 & 0 & 4.29 & 23.1 \\
\hline Nicaragua & 6 & 18.52 & 3 & -0.44 & -0.87 & 1 & 0.74 & 70.28 \\
\hline Panamá & 3 & 25.32 & 1.5 & -0.24 & -0.14 & 4 & 2.15 & 33.93 \\
\hline Paraguay & 6 & 11.03 & 3.5 & -1.22 & -1.29 & 1 & 0.67 & 55.81 \\
\hline Perú & 5 & 8.38 & 2.5 & -0.2 & -0.47 & 0 & 1.14 & 2.95 \\
\hline Dominican Republic & 4 & 19.64 & 2 & -0.39 & -0.41 & 0 & 3.01 & 59.58 \\
\hline San Cristóbal y Nieves & 2 & 23.84 & 1.5 & 0.4 & -0.06 & 0 & 2.43 & 0 \\
\hline Santa Lucía & 2 & 19.18 & 1.5 & 0.4 & -0.06 & 6 & 2.31 & 0 \\
\hline San Vicente y las Granadinas & 3 & 21.19 & 1.5 & 0.4 & -0.06 & 0 & 1.43 & 0 \\
\hline Suriname & 4 & 22.13 & 1.5 & 0.19 & -0.16 & 0 & 4.99 & 0 \\
\hline Trinidad \& Tobago & 4 & 18.88 & 3 & -0.04 & 0.47 & 0 & 20.47 & 4.97 \\
\hline Uruguay & 2 & 31.86 & 1 & 0.79 & 0.51 & 1 & 1.62 & 100 \\
\hline Venezuela & 8 & 12.21 & 3.5 & -0.94 & .1 .14 & 0 & 6.5 & 5.38 \\
\hline Promedio & 4.58 & 17.56 & 2.48 & -0.08 & -0.14 & 1.33 & 3.08 & 31.49 \\
\hline
\end{tabular}

Fuente: Elaboración propia. 